\title{
The Role of the Product as an Element of Marketing Mix in the Field of Culture
}

\author{
Tatiana Golubkova*, Alla Iljina \\ European Business School, Baltic International Academy, Latvia
}

Copyright $@ 2015$ Horizon Research Publishing All rights reserved.

\begin{abstract}
The article considers the issues of definition of the cultural product as an element in the marketing mix. During the analysis of a number of definitions which give to the cultural product the modern researches, as well as its systemization, the authors suggest those basic categories of the classification of cultural product which according to their opinion have the most significant value in the terms of marketing.
\end{abstract}

Keywords Cultural Product, The Classification of the Product, Goods, Services, The Form of Consumption

\section{Introduction}

Problem statement: Today there is no unambiguous definition of cultural product because of its extreme diversity. In the most general form as such, can be defined goods and services, contributing to the formation and satisfaction of a specific group of human needs - cultural. The main directions of cultural needs include artistic and aesthetic, educational, entertaining, recreational and others. Such diversity significantly complicates the classification of cultural products as each of them describes just separate aspects and often it seems quite difficult to establish clear boundaries between different groups. Thus, the consideration of this issue is relevant both for the development of the theoretical base of marketing in the field of culture and for an appropriate practical activity and requires to lead available at the present stage of development of this field of knowledge to the corresponding systematization. In this regard, the goal of this research is the determination of the content of the cultural product and its value in the marketing mix on the basis of suggested classification.

It is important to note that to the topic, devoted to the cultural product as an element in marketing mix, in the scientific literature is not paid a due attention. As a result the definition of the role and importance of the cultural product in the marketing mix, the study of factors, influencing on the formation of the cultural product, along with the other elements of the marketing mix and their practical use is hampered and require the further study.

\section{Methods}

As the general scientific methods of research in the paper were used the methods of analysis, synthesis and deduction by the means of which were considered the theoretical aspects of definition of the cultural product, were analyzed its main topologies and identified their drawbacks. The use of method of formalization, allowing setting the theoretical patterns and playing an important role in specifying the scientific concepts, contributed to the definition of cultural product as a category of marketing. For the regulation of the examined objects was used, the scientific method of classification and the results of the use contributed to the formation of new topology of the cultural product and identification of its role in marketing mix.

\section{The Definition of Cultural Product}

\subsection{The Differentiation of Approaches to the Scientific Definition of the Cultural Product}

In the most modern researches the concepts "cultural product" and product of cultural establishment are used as synonyms, while some scientists, in particular, G. M. Kafarov points at a significant difference of these concepts as cultural establishments today provide additional services, servicing for satisfaction not only of cultural, but other human needs. [1.7].

On the basis that the cultural product acts as the main object of supply and demand on the socio -cultural market, the researcher M.V. Rukosueva defines it, firstly, as a benefit provided to the cultural establishments in the form of goods and services, presenting the cultural values, meanings, ideas, ethical and moral norms, images, cultural patterns, presentation, and secondly, as a result of process of ideal formation, embodied in the real (as representative) or immaterial (as the ideal) form, designed to meet the needs of 
the higher - order (secondary, i.e., social, spiritual, communicative and etc.). [2].

In the English literature has formed its own specificity of use of this term. The term "cultural product" has been actively used recently - at the end of XX century due to the emergence of cultural industries, since the culture has been recognized as capital and material intensive field of human activity.

Thus, in the documents of UNESCO the concept "cultural product" is used for the denotation of cultural goods and services. At that the cultural services are defined as "services" aimed at the satisfaction of cultural interests or needs", but cultural goods as "consumer goods" that convey the ideas, symbols, imagination, concerning the way of life". [3].

Today, UNESCO allocates 10 categories of cultural goods and services:

Table 1. The categories of the cultural product of UNESCO

\begin{tabular}{|c|l|}
\hline 1. & $\begin{array}{l}\text { Cultural heritage (historical monuments,archeological heritage, } \\
\text { museological heritage, archival heritage and other forms of } \\
\text { cultural heritage); }\end{array}$ \\
\hline 2. & $\begin{array}{l}\text { Printed matter and literature (books and pamphlets, newspapers } \\
\text { and periodicals, library services); }\end{array}$ \\
\hline 3. & $\begin{array}{l}\text { Music and the performing arts (live music, music theatre, audio } \\
\text { and audio visual records); }\end{array}$ \\
\hline 4. & $\begin{array}{l}\text { Performing arts (drama theatre, dance, circus, pantomime and } \\
\text { other types of visual arts); }\end{array}$ \\
\hline 5. & $\begin{array}{l}\text { Visual arts (painting, sculpture, graphic arts, art handicraft, } \\
\text { creative- artistic photography and other forms of visual arts); }\end{array}$ \\
\hline 6. & Audio and audiovisual media (cinema, photography, video); \\
\hline 7. & Radio, television, video; \\
\hline 8. & $\begin{array}{l}\text { Socio-cultural activities (associative life, multipurpose } \\
\text { sociocultural facilities); }\end{array}$ \\
\hline 9. & Sports and games; \\
\hline 10. & $\begin{array}{l}\text { Environment and nature (natural environment, urban } \\
\text { environment); }\end{array}$ \\
\hline
\end{tabular}

Thus, it can be stated that the concept of cultural product recently has expanded significantly and is considered both in the context of activity of traditional field of culture and in the context of rapidly growing cultural industry. The study of marketing in the field of culture as one of the main classifications suggests the divisions into the products of business activity (its production and distribution are initially aimed at profit extraction) and products offered by non-commercial cultural organizations that orient its activity at the solution of social, cultural and educational problems. In the first case are used the classical marketing technologies aimed at the achievement of profitability and efficiency of the company on the market, while the marketing of non-commercial organizations of culture has its own specificity that allows allocating it in a separate scientific direction.

One of the peculiarities of marketing of non-commercial activity is its multidimensionality. As G.L. Tulchinsky notes in non-commercial field of culture the subject of effective demand often does not coincide with the direct consumer that leads to the emergence of two markets - the market of consumers and the market of donors $[4 ; 36]$. The last one currently is being developing the most actively because of the potential opportunities of advertising, improvement of image, reputation, improvement of the social status that can be provided by cultural field.

According to the opinion of some authors, in particular, E.N. Voronovoi and M.K. Koshkinoi among the products of the cultural field can be allocated the categories of basic and additional goods and services. To the basic refer those products that serve for the achievement of statutory objectives of activity of organization culture, i.e., aimed at the implementation of its mission. Thus, to the core services of museums can be referred their exhibition and educational activity. Additional services not coming into contradiction with the main objectives of cultural establishments contribute to the satisfaction of needs of customers in information management, food, souvenir gifts and etc. [5; 64].

\subsection{The Definition of the Cultural Product in Marketing}

The researchers E. L. Schekova and G. L. Tulchinsky offer as a basis for the classification of products of cultural field to use the criterion of authenticity and thus to divide them into primary and secondary. To the primary product they refer those "material and non-material benefits that are offered to the consumer in the real form (picture, sculpture, performance and etc.). The secondary product represents the copies of the primary benefits as well as the results of conversions of non-material products into material, the goals of production of which is both popularization of primary benefits and the promotion of separate individuals and organizations. As a secondary product can act the reproductions, discs with audio and video records, slides, etc. $[4 ; 38]$.

In its turn, A. Kazakov systematizes the cultural products, depending on their content and form, thus, the main groups here are:

Works of art, representing the art forms of performance results (works in the field of literature and art, for example, compositions, musical, cinematographic works, paintings, sculptures, etc.);

- Information cultural products (products of the mass media, possessing the "cultural" content);

- Performance activity (the activity of individuals, participating in the execution of works of art and creating new synthetic products);

- The services of cultural establishments in organization of production and/or the consumption of artistic and literary works, performing and applied arts;

- Cultural tourism, representing a specific service to ensure the familiarization with the originals of culture and arts [6].

In order to highlight the specificity of non-commercial market of cultural products which is mainly represented by the field of art in English literature is most often used the concept arts marketing. In scientific works of foreign experts in marketing, in particular, F. Kottler, J.S Bernstein, and S. 
Botti most of the focus is on the products of such non-commercial sectors of culture as performing arts and visual arts. Using these categories Simona Botti suggests adding the classification of cultural product by its belonging to the high culture or popular culture as well as by the allocation of artistic goods and services [7] (See Figure 1).

As shown in Figure 1 of the third-dimensional model of classification of cultural product distinguishes three main characteristics: 1) a method of influence on the audience (performing arts/visual arts), 2) focus on the creative aspect/orientation to the commercial success (elite art/popular art), 3) according to the type of product (goods/services).

The products of visual arts (painting, sculpture, photography, etc.) distinguish a direct impact on the feelings and emotions of spectator, while the products of performing art, the examples are the concerts of classical and popular music, representing by performers.

The division of cultural products, relating to the high (elite) or popular art in this classification is related not only to the artistic level of works, as to their commercial orientation.

If the product of popular culture is largely focused on the commercial success, then, for the works of high art are not compulsory component and its production inevitably associated with the government subsidies or other forms of external financial support.

Categories of cultural goods and services as notes S. Botti do not have a clear distinction. Generally accepted in the marketing division of goods and services, based on the intangible, inhomogeneous, non-separable into production and consumption and non-retentive nature of the last can be used with the sufficient degree of conditionality as often the product can represent a unity of goods and services (product-service continuum). The example of such cultural product can serve a concert of symphonic music: its simultaneous performance represents a cultural service and replicate of audio recording - goods.
This classification seems worthwhile, however, it is not exhaustive and it is not without significant drawbacks, primarily, due to blurring of its criteria, unable to build clear boundaries between different groups of cultural products as well as in the form of division into visual and performing arts which has a cultural, but not economic nature.

\section{The Classification of Cultural Product}

Taking into the consideration the above mentioned remarks as well as the emergence of new types of cultural products, requiring the introduction of new, not previously represented groups, it is suggested the following classification, in which the primary focus is on the most categories from the point of view of marketing (Figure 2). The first reason according to which is suggested to systemize the cultural product is the form of its consumption. Here it is important to note the emergence of completely new group of cultural product which was not allocated in a separate type intangible goods, represented by the virtual digital products, available to consumers in the form of mobile applications and file formats of MP3, MP4, FLV and others. Thus, according to the form of consumption the cultural products can be divided into three main groups: 1) tangible goods (audio and video discs with the recording of music, movies, books, pictures, etc.); 2) intangible goods (music files of MP3 format, video files of MP4 format, containing fiction films or records of performances, mobile applications of theatres and museums) and 3) cultural services (concerts, performances, excursions, etc.).

Depending on the goals of offer the cultural product can have 1) commercial or 2) non-commercial nature. In the first case the sale of goods and provision of services associated with the profit-making, if it is unprofitable the production ceases.

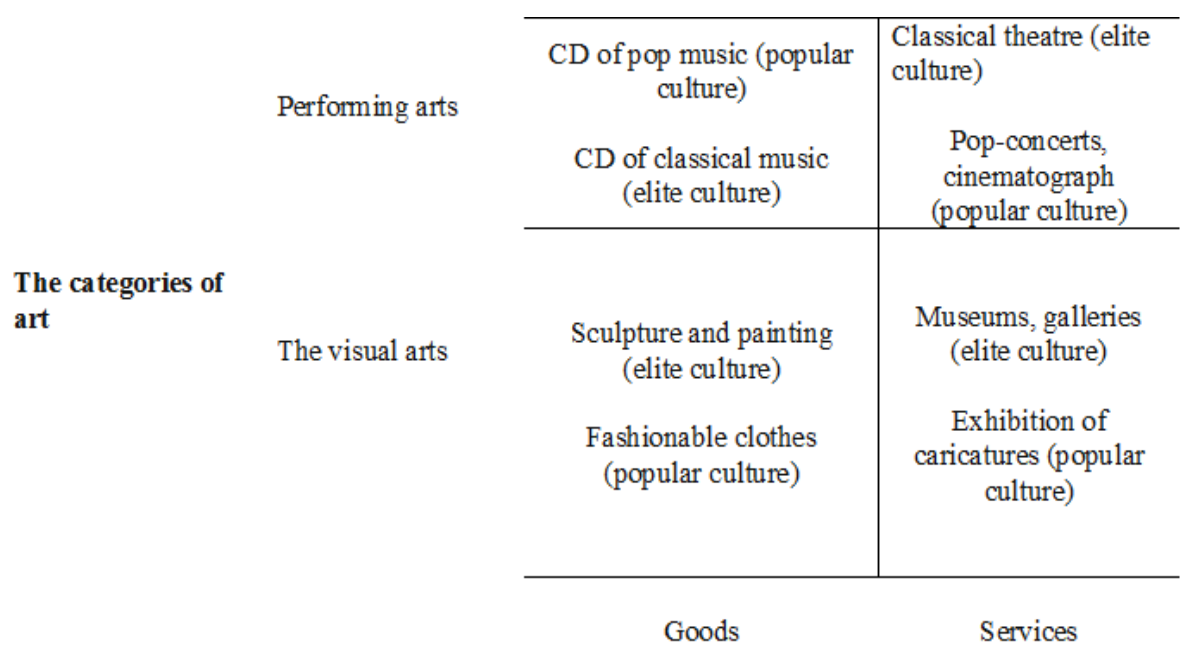

The nature of product

Figure 1. Third - dimensional classification of the cultural product 
Cultural product

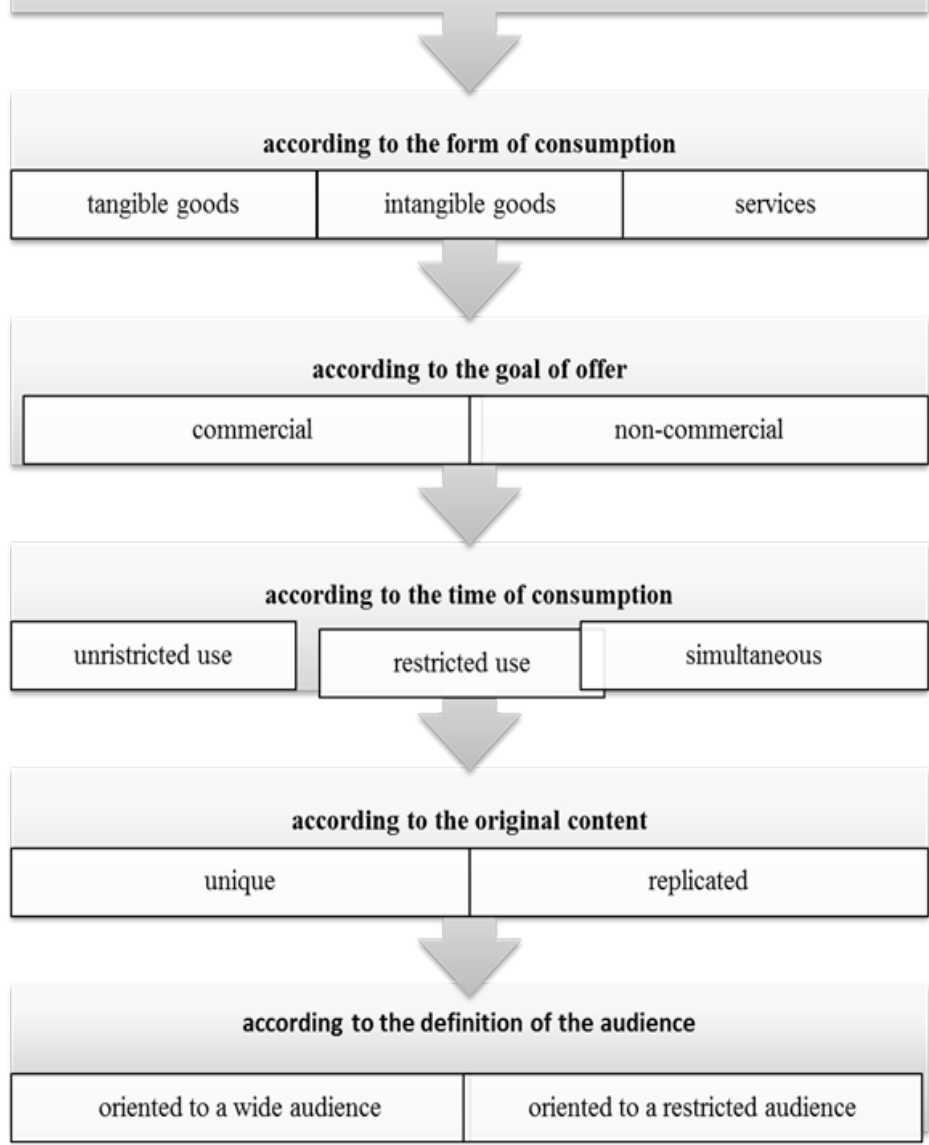

Figure 2. The classification of cultural product

In the second case, the manufacturer pursues mainly socially important, cultural and educational objectives, the commercial success of the cultural product is not compulsory that, however, does not mean its unprofitability undoubtedly. To the non-commercial cultural products can be referred CD records of music concerts, fictional films on DVD, the services of cinemas and etc., in its turn, the non-commercial cultural products are represented by goods and services, usually, created with the financial support of the state, sponsors and patrons (theatrical performances, exhibitions of art museums, festivals, etc.).

The following reason for the classification of cultural products means their division, depending on the time of consumption. Here can be allocated 1) the products of unrestricted consumption (items of paintings and sculptures, books, records in music $\mathrm{CD}$ ); 2) products of restricted consumption (theatrical subscriptions (seasonal or with a fixed number of performances)); 3) simultaneous services (sessions of cinemas, concerts, theatre performances).

The cultural products can also be differentiated according to the original content. Thus, it is necessary to distinguish 1) unique products (works of visual and performing arts) and 2) replicated cultural products (reproduction of arts, audio recording of concerts, and video recording of theatrical and opera performances). Replicated cultural products can meet the demand of wide mass audience, as well as to contribute to the promotion of the original products, as a rule, less accessible.

Along with this, according to the definition of the audience the cultural products can be divided into 1) intended for the wide audience and 2) intended for the restricted audience. The last one is oriented to the restricted age, national, and etc., audience (for example, children's shows, duplicated for particular language, movies, etc.).

\section{The Role and Significance of the Cultural Product in the Marketing Mix}

The suggested classification of the cultural product in five main directions gives ground to assume that the product as a category of marketing to a large extent is determined namely by these categories. This topology simplifies the further definition of the role and significance of the cultural product in the marketing mix as a whole. The formation of the 
cultural product in this category allows becoming the starting point for the formation of price, place and its promotion on the market. However, it should be stressed that each element in the marketing mix will be formed, taking into the consideration all the peculiarities of subsequent directions of the above mentioned classification (See. Figure 2).

Taking into the consideration that the cultural product is aimed at the satisfaction of needs, first of all, aesthetic, it acquires its value, taking into the consideration the peculiarities of its field of formation, in this case - the purposes of proposal. Taking into the consideration these peculiarities is formed price, place and use the different tools of promotion. In its turn, on the component of the cultural product influences its originality that also determines the different approaches to the formation of price, distribution channels and distribution. The orientation to a specific audience, whether it is wide or restricted, requires a special approach to the price-formation policy, determination of the place and use of tools of promotion.

The above stated shows a special role and significance of the cultural product in the formation and use of all elements of marketing mix. The correct understanding of the theoretically developed classification of the cultural product (Figure 2) and its implementation in practice will help the manufacturer successfully to implement his/her activity, but suggested in such conditions the cultural product will bear the customer value and customer satisfaction.

\section{Conclusions}

The carried out research has shown that in the scientific literature there is no precise definition of the cultural product and its clear classification, the previously suggested topologies don't provide an opportunity of effective inclusion of cultural product in the marketing mix and thus don't contribute to the solution of the vital tasks, facing the cultural establishments. Accordingly, the suggested definition of the cultural product as an element of marketing mix, directly related to the systemization of goods and services of the cultural field, aimed at the creation of maximum customer. The classification of the cultural product in five basic reasons: according to the form of consumption, goal of proposal, time of use, content and determination of the audience allows more qualitatively carrying out the subsequent research of such elements of marketing mix as price, place and promotion. However, it should be noted that on the development of the cultural product and effective marketing mix as a whole, the significant influence also have the external factors, such as: demographic, political, economic, socio-cultural, technological and etc., that correspondingly is reflected on the emergence of new forms of cultural product as well as on its distribution and promotion. This fact requires the carrying out of in-depth and comprehensive analysis of external environment and further researches, aimed at the improving of effective marketing in the field of culture.

\section{REFERENCES}

[1] Kafarov G.M., Galuckij G.M., Mazun O.V. Razvitie platnyh uslug v kul'turno-prosvetitel'skih uchrezhdenijah. M., 1988. 72 p. (in Russian)

[2] Rukosueva M. V. Kulturnyj produkt: k opredeleniju ponjatija. Online available from conf.sfu-kras.ru/sites/mn2014/pdf/d01/s58/s58_017.pdf （in Russian)

[3] Sistema statistiki kultury UNESCO - 2009 U NESCO-UIS. Online available from

http://www.uis.unesco.org/culture/Documents/framework-cu ltural-statistics-culture-2009-rus.pdf (in Russian)

[4] Tulchinskij G. L., Shekova E. L. Menedzhment v sfere kultury, 4th ed. - SPb.: Lan', Planeta muzyki, 2009. - 528 p. (in Russian)

[5] Shekova E. L. Osobennosti marketinga nekommercheskih organizacij kul'tury: rossijskij opyt, - Vestnik SPbGU. Ser. 8 2003. Vol. 2, No.16., 55-75. (in Russian)

[6] Kazakov A.A. Marketing v SKS. Online available from files.lib.sfu-kras.ru/ebibl/umkd/1466/u_lectures.pdf (in Russian)

[7] Botti S. What role for marketing in the arts? An analysis of arts consumption and artistic value. Online available from http://www.gestiondesarts.com/en/what-role-for-marketing-i $\mathrm{n}$-the-arts-an-analysis-of-arts-consumption-and-artistic-value \#.vfz-spmsv6q 